\title{
ENSURING ECONOMIC EFFICIENCY OF FLEXIBLE FIXTURES IN MULTIPRODUCT
} MANUFACTURING

\author{
VITALII IVANOV (1) OLEKSANDR LIAPOSHCHENKO \\ YULIIA DENYSENKo ${ }^{\circledR}$ IVAN PAVLENKo ${ }^{\circledR}$
}

\begin{abstract}
A B S TR A C T
The first-priority directions for modern engineering, especially for multiproduct manufacturing, include the intensification of manufacturing processes, increasing the efficiency of technological equipment, and reducing the time required to implement technological solutions. Fixture design is a complicated and time-consuming process that requires considering many parameters of the closed-loop technological system "machine tool - fixture - cutting tool - workpiece". One machined part can have several fixture layouts corresponding to all specified parameters; however, their effectiveness differs depending on production conditions. Search for an optimal fixture for specified production conditions is an essential stage of production planning. It has been proved that the efficiency of a manufacturing process should be assessed using single economic indicator - the cost of machining, which considers the costs of time, the total costs for process realisation, and a batch of parts. The paper aims to substantiate the efficiency of manufacturing processes in machining complex parts using flexible fixtures by developing a mathematical model that considers the cost of time, the cost of implementing the manufacturing process, and the batch value of parts production. This approach estimates the efficiency of manufacturing processes for machining complex parts and choosing the flexible fixture layout that corresponds to specific production conditions. It was proved that flexible fixtures could be effectively used for machining small batches of parts with frequent readjustments to new workpieces and short-term machining. A tendency has been established that the higher number of nomenclature of parts contributes to expanding the scope of the effective use of flexible fixtures.
\end{abstract}

KEY WORDS

flexible manufacturing, fixture design, multiaxis machining, cost of machining

10.2478/emj-2021-0004 pages: $53-62$
Vitalii Ivanov

Sumy State University, Ukraine ORCID 0000-0003-0595-2660

Corresponding author: e-mail: ivanov@tmvi.sumdu.edu.ua

Oleksandr Liaposhchenko

Sumy State University, Ukraine ORCID 0000-0002-6657-7051

Yuliia Denysenko

Sumy State University, Ukraine ORCID 0000-0002-9816-2862

Ivan Pavlenko

Sumy State University, Ukraine ORCID 0000-0002-6136-1040

\section{INTRODUCTION}

In modern engineering, the main challenge is to reduce the time spent on the design and manufacture of products, which is continually becoming more complicated, since increasingly more varieties of similar products are needed in today's market. Ivanov et al. (2019) noted that the range of engineering products had increased by 2.5 times, and it is also important to note the growing complexity as well as requirements for accuracy and quality. Therefore,

Ivanov, V., Liaposhchenko, O., Denysenko, Y., \& Pavlenko, I. (2021). Ensuring economic efficiency of flexible fixtures in multiproduct manufacturing. Engineering Management in Production and Services, 13(1), 53-62. doi: 10.2478/emj-20210004 
metalworking equipment and processes must become more flexible to ensure the competitiveness of products and the response to market needs as well as to reduce market entry time. This necessitates to develop and implement fundamentally new design and technological solutions for using automated technological equipment as multiaxis machining centres to locate, clamp, and orient workpieces in the machining area, ensuring high-quality products. The first-priority directions in the development of modern manufacturing engineering technologies, especially multiproduct manufacturing, include intensified manufacturing processes and increased efficiency of technological equipment. Given the increase in the range of engineering products, flexible fixtures form the basis for ensuring high product quality, increasing productivity, and reducing the complexity of manufacturing processes.

The efficiency of implemented fixtures depends on several factors, the most important of which is the range of machined parts. The minimum batch size of parts is limited by specific costs for developing and debugging fixtures. As the batch size increases, the unit costs decrease, which contributes to the efficiency of fixtures.

The investigation into modern experience has shown that many research efforts are devoted to efficiently functioning manufacturing systems, but no single approach considers all these factors.

Therefore, this paper aims to substantiate the efficiency of manufacturing processes for machining complex parts using flexible fixtures by developing a mathematical model that considers the cost of time, the cost of implementing the manufacturing process, and the batch size. Research objectives include:

- the analysis of modern approaches to the effectiveness of flexible fixtures in multiproduct manufacturing;

- the development of a mathematical model that substantiates the efficiency of manufacturing processes for machining complex parts using flexible fixtures based on comparative economic efficiency and considering the cost for implementing the manufacturing process and the batch size;

- piloting the practical implementation of the proposed mathematical model using batches of differently configurated forks.

The paper contains a literature review with the identified research problem and recent research results by other scientists, the research methodology with the proposed scientific approach, results with calculated data for different production conditions, the discussion substantiating achieved scientific novelty and recommendations for practical implementation, and, finally, conclusions that summarise the main results of research.

\section{LITERATURE REVIEW}

The manufacture of engineering products saw the increase in the share of the CNC multiaxis machining centres aimed at intensification and automation of production, which can be significantly restrained by structurally obsolete (inflexible) fixtures that require much more auxiliary time for changing coordinates of the machined surfaces. This can be corroborated by the fact that under current typical conditions of rapid development and use of the latest technologies, the engineering industry is constantly introducing new and more efficient manufacturing processes and equipment for implementation at enterprises around the world.

As confirmed by the following data, fixtures play one of the most significant roles in engineering product manufacturing. According to Kotliar et al. (2019), the share of fixtures in the total amount of tooling is 70-80\%. Hashemi, Shaharoun and Sudin (2014) proved that the production costs for the design and manufacture of fixtures could reach $90 \%$. Bi and Zhang (2001) reported that costs of fixtures comprise $10-20 \%$ of the total costs of manufacturing systems. Nixon (1971) maintained that up to $40 \%$ of defective parts in machining might have occurred due to imperfections of fixtures. Rong and Zhu (1999) stated that approx. $70 \%$ of new designs of fixtures were a modification of existing ones.

The development of modern, efficiently functioning manufacturing systems requires careful production planning. To date, world engineering is dominated by multiproduct manufacturing, which is characterised by a wide range of products, the reduction of unproductive time, the introduction of highly efficient CNC multiaxis machining centres, and the decrease in the number of technological equipment units. Ivanov et al. (2019) demonstrated the need to develop and implement fixtures, providing multiaxis machining of parts with sufficient tool availability.

The design of flexible fixtures is a complicated and time-consuming process that requires considering many parameters. Kotliar et al. (2019b) focused on production conditions; Krol and Sokolov (2018) considered technological capabilities of metal-cutting 
equipment; Li, Chen and Shi (2016), Kostyuk, Nechyporuk and Kostyk (2019), and Kostyuk (2019) examined parameters of cutting tools; Bakker et al. (2013) and Shaik, Rao and Rao (2015) studied design and technological features of parts; Basova et al. (2018) and Sokolov, Krol and Baturin (2019) investigated dynamic characteristics; Denysenko et al. (2019) and Dynnyk et al. (2020) evaluated quality indicators; and Yarovyi and Yarova (2020) appraised energy-efficient criteria. Meanwhile, Qin et al. (2010) presented a literature review on existing fixture systems, their functionality, design features, and sufficient use.

Ansaloni et al. (2013) and Matteo et al. (2013) noted that when designing the manufacturing process of machining parts for the automotive industry with $\mathrm{CNC}$ machines, it is crucial to strive to intensify machining processes, increase the flexibility of equipment and processes, and productivity levels. Son and Park (1987) stated that productivity, quality, and flexibility were key indicators of production efficiency integrated into the model for evaluating manufacturing systems used to justify investment in manufacturing systems. Based on Basova et al. (2018) and Stepanov et al. (2019), the main provisions for calculating the productivity of machining parts intensify cutting modes when choosing the optimal parameters of fixtures.

Many research efforts by Mehrabi et al. (2002), Setchi and Lagos (2004), Hasan, Jain and Kumar (2014), and Förstmann et al. (2017) confirmed that equipment was essential for modern production. Thus, the requirements for accuracy, flexibility, rigidity, performance, and reliability are paramount and affect the effectiveness of manufacturing processes.

Ji et al. (2013) offered an effectiveness-driven modular design method that considers all effectiveness scenarios and balances the granularity and composition of modules among all possible forms during the clustering process to maximise the effectiveness of modules throughout the product life-cycle as much as possible.

Sonmez et al. (2019) found that the overall equipment effectiveness was considered a performance indicator for manufacturing equipment. Particularly, two types of uncertainty are considered in production, namely, speed and stoppage duration, which are used to calculate components of the overall equipment effectiveness.

Sarker et al. (2001) made a critical review and a comparative study of different grouping efficiency measures. Special emphasis was given to evaluating clustering solutions in the block-diagonalisation of the machine-part incidence matrix.
Li et al. (2007) proposed using the weighting factor for the incidence matrix, thus defining a new measurement of efficiency for multi-dimensional group technology. The investigation into modern experience has shown that many studies focused on efficiently functioning manufacturing systems.

Neely (1999) noted that group technology positively impacted on cost-based efficiency analysis of fixtures, making the design more efficient in terms of quality and productivity.

McIntosh et al. (2000) examined that the trend to reduce the cost and time in fixture design positively influenced the use of metal-cutting equipment, which enabled a continuous flow of production. Elkins et al. (2004) focused on the cost and time effectiveness in using flexible manufacturing systems in the automotive industry.

According to Sethi and Sethi (2001), in multiproduct manufacturing, the variety of products requires a flexible response by the production systems without compromising cost-effectiveness.

Brettel, Klein and Friederichsen (2016) stated that the fast reconfiguration of systems and processes allowed maintaining excellent product performance at low costs.

Erdem et al. (2017) highlighted that the efficiency of a flexible fixture is a multi-dimensional task. However, their overall cost depends on investment and setup costs, which have a negative effect on efficiency while increasing.

However, no single approach considers the cost of time, the cost of implementing the manufacturing process, and the batch value of parts production when machining complex parts using flexible fixtures. This substantiates the relevance of the chosen research direction, and the list of research tasks is formed.

\section{RESEARCH METHODS}

The scope of the effective use of equipment is a set of parts produced by a given machine at a minimal cost compared to the cost of production on another machine or a group of machines that correspond to the technological problem according to specified production conditions.

The same part can be produced on different pieces of equipment designed for machining under different production conditions. In each case, the choice of equipment determines the efficiency of the manufacturing operation. If the use of different equipment can ensure the machining of parts of the 
required quality, the most effective equipment should be chosen based on economic indicators.

The scope of the effective use of equipment is established by comparing competing variants based on the technical and economic model, which considers the machining of parts of identical batches under the conditions of multiproduct manufacturing and compares only operations of machining of parts with different indicators.

A single economic indicator should assess the efficiency of the manufacturing process - the cost of machining $(\mathrm{C})$, which considers the cost of time $(\mathrm{T})$, the cost of manufacturing process implementation $(\mathrm{S})$, and the batch size $(\mathrm{N})$. Among the options of manufacturing processes for the manufacture of parts, the one that provides the lowest cost of machining is considered to be effective

$$
\mathrm{C}(\mathrm{T}, \mathrm{S}, \mathrm{N})=\min \left\{\mathrm{C}_{\mathrm{typ}} ; \mathrm{C}_{\text {prop }}\right\}
$$

The machining cost is calculated for the typical $\left(C_{\text {typ }}\right)$ and the proposed ( $\left.C_{\text {prop }}\right)$ manufacturing processes according to the proposed dependence:

$$
C_{\text {typ.;prop. }}=\sum_{j=1}^{f} \sum_{i=1}^{m} C_{i}^{<j>}
$$

where $f-$ the number of fixtures for the implementation of the manufacturing process; $m-$ the number of operations of a manufacturing process; $j-$ number of fixtures for realising the considered manufacturing process; $i$ - the operation number of the considered manufacturing process.

For the conditions of multiproduct manufacturing, it is advisable to estimate the cost of machining considering the cost of power energy $E$, depreciation of equipment $A$, operation of fixtures $F$ and cutting tools $R$

$$
C=E+A+F+R
$$

The formula calculates power energy costs

$$
E=P_{e n} \cdot N_{d} \cdot K_{N} \cdot T_{c} /(K \cdot 60)
$$

where $P_{e n}-$ the cost of $1 \mathrm{~kW}$ of power energy, UAH; $N_{d}$ - established power of electric motors of the machine, $\mathrm{kW} ; K_{N}$ - load factor by power (0.6-0.9for roughing operations, $0.3-0.6$ - for finishing operations); $T_{c}$ - cutting time, $\min ; K-$ coefficient that considers different costs (0.9-0.95).

The formula calculates equipment depreciation costs

$$
A=P_{e} \cdot K_{a} \cdot T_{m c} /\left(F_{t} \cdot K_{e} \cdot 60\right)
$$

where $P_{e}$ - book value of equipment, UAH; $K_{a}-$ depreciation coefficient, which determines the payback period of the equipment $(0.1-0.15-$ for special equipment, $0.15-0.2-$ for the main type of machines)); $T_{m c}-$ the machining-calculation time of operation, min; $F_{t}-$ actual annual fund of equipment operation, hours; $K_{e}-$ equipment load factor.

The formula calculates the cost of operating the fixtures

$$
\mathrm{F}=\mathrm{P}_{\mathrm{f}} \cdot(\mathrm{a}+\mathrm{b}) / \mathrm{N}
$$

where $P_{f}-$ the cost of the fixture, UAH; $a-$ depreciation coefficient $(0.3-0.5) ; b-$ current repair cost coefficient (0.1-0.2); $N$ - number of batch parts for which the machine tool is intended.

Given that the same machining conditions and cutting tools are used for both variants of the manufacturing processes, operating costs of the cutting tools are assumed to be the same for both variants and are not considered in further calculations.

A mathematical model is obtained by substituting formulas (4)-(6) in (3) and performing certain mathematical transformations, as well as allocating time costs $\left(T_{c}, T_{a}, T_{p}\right)$, the cost of implementation of manufacturing processes $\left(S_{1}, S_{2}, S_{3}\right)$ and the batch size $(N)$,

$$
\begin{aligned}
\mathrm{C}_{\mathrm{i}}^{<\mathrm{j}>}=\mathrm{T}_{\mathrm{ci}}^{<\mathrm{j}>} & \cdot \mathrm{S}_{1 \mathrm{i}}^{<\mathrm{j}>}+\left(\mathrm{T}_{\mathrm{ci}}^{<\mathrm{j}>}+\mathrm{T}_{\mathrm{ai}}^{<\mathrm{j}>}+\mathrm{T}_{\mathrm{pi}}^{<\mathrm{j}>}\right) . \\
& \cdot \mathrm{S}_{2 \mathrm{i}}^{<\mathrm{j}>}+\mathrm{S}_{3 \mathrm{i}}^{<\mathrm{j}>} / \mathrm{N}^{<\mathrm{j}>}
\end{aligned}
$$

where $T_{c i}^{<j>}$ - the elements of the matrix of the cutting time by size $m \times f ; T_{a i}^{<j>}-$ the elements of the matrix of the auxiliary time by size $m \times f ; T_{p i}^{<j>}$ - elements of the matrix of preparatory time by size $m \times f ; S_{1 i}^{<j>}-$ elements of the matrix of power energy costs for the implementation of the manufacturing process by size $m \times f ; S_{2 i}^{<j>}-$ elements of the matrix of equipment depreciation costs by size $m \times f ; S_{3 i}^{<j>}-$ elements of the cost matrix for the design and operation of fixtures by size $m \times f$.

Thus, the task is to choose the manufacturing process, which allows incurring the minimum cost of machining among the proposed options. The problem of minimising the cost function (7) is solved consistently for competing variants of the manufacturing process, considering technical limitations. The results were evaluated using comparative economic efficiency, the ratio of costs in the implementation of typical and proposed manufacturing processes 
comparative economic efficiency, the ratio of costs in the implementation of typical and proposed manufacturing processes

$$
\mathrm{E}=\mathrm{C}_{\mathrm{typ}} / \mathrm{C}_{\text {prop }}
$$

\section{RESEARCH RESULTS}

The practical implementation of the proposed mathematical model on the example of batches of differently configured plugs illustrated that the effective implementation of the proposed manufacturing process differed depending on the number of types and sizes of machined parts as changes in time consumption.

When machining fork-type parts, the proposed manufacturing process based on the multiaxis machining is effective provided that the batch volume of the workpiece does not exceed 50 pcs. (Fig. 1). For these conditions, the cost of operating flexible fixtures is lower than the cost of a set of dedicated fixtures.

The ability to process several nomenclatures in flexible fixtures allows expanding the scope of the effective use of proposed manufacturing process to 66 and 71 parts in the batch with two and three nomenclatures of workpieces, respectively (Fig. 2, 3). The cost of machining according to the proposed manu-

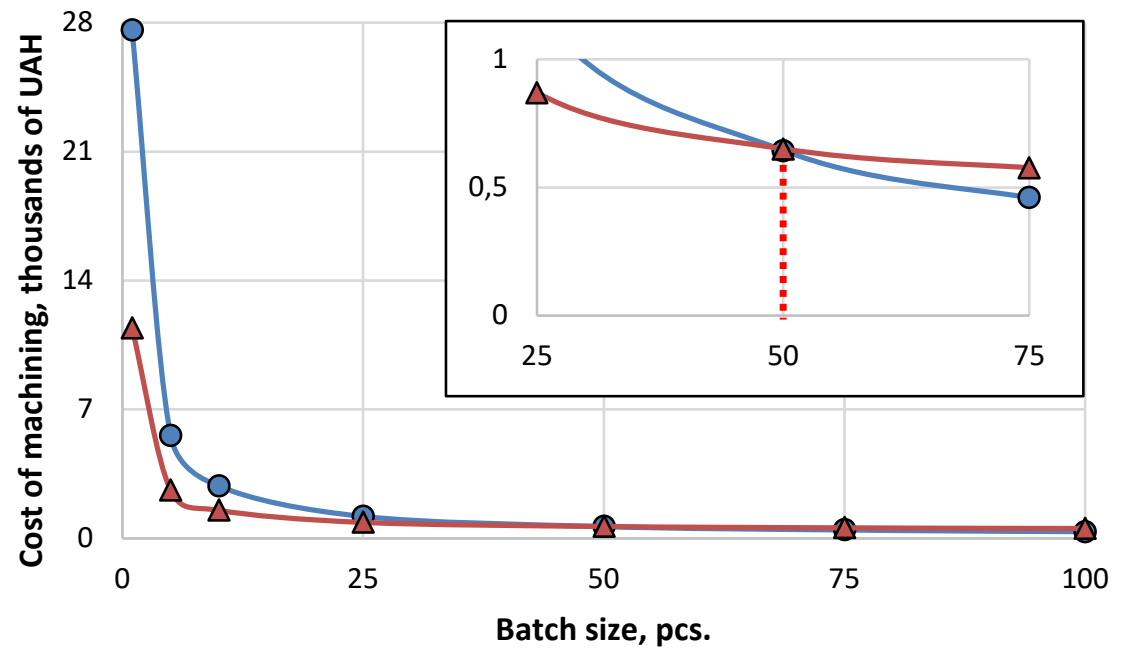

- Typical process $(n=1) \quad \triangle$ Proposed process $(n=1)$

Fig. 1. Cost of machining parts depending on the batch size when machining one nomenclature of parts

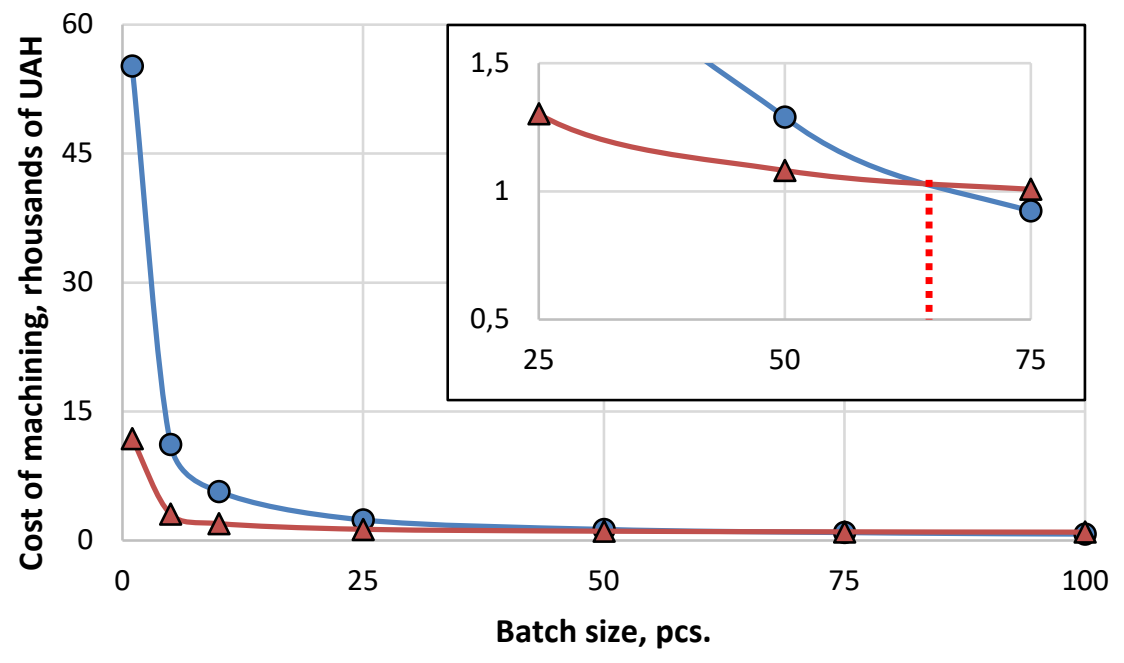

- Typical process $(n=2) \quad \triangle$ Proposed process $(n=2)$

Fig. 2. Cost of machining parts depending on the batch size when machining the two nomenclatures of parts 


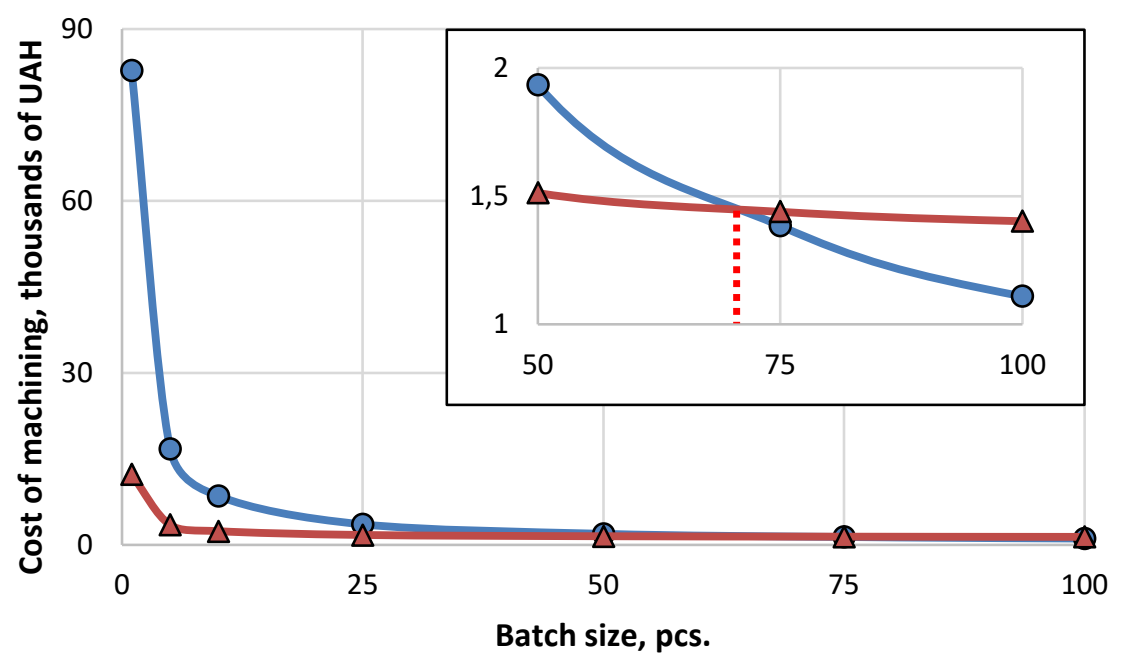

O-Typical process $(n=3) \quad \Delta$ Proposed process $(n=3)$

Fig. 3. Cost of machining parts depending on the batch size when machining the three nomenclatures of parts

facturing process is reduced, and the comparative economic efficiency equals 1.19 and 1.28 for two and three nomenclatures of machined parts, respectively, when calculating for a batch of parts with 50 pcs.

Thus, the determined general tendency is to increase the batch size that can be machined according to the proposed manufacturing process while increasing the number of fixture nomenclatures.

The productivity of machine tools significantly depends on the share of the cutting time in the structure of machining time. It has been established that the cutting time influences the choice of a manufacturing process and the determination of the effective scope's limit.

Further research revealed a general trend that a shorter machining time indicates the effectiveness of the proposed manufacturing process. E.g., the research dependencies of the cost of machining on the batch size when machining one to three nomenclatures of parts at $\mathrm{Tc}=1 \mathrm{~min}$ allowed to establish that the proposed manufacturing process was useful when machining a batch of parts up to $90 \mathrm{pcs}$. Increasing the number of standard sizes of parts allows expanding the scope of the effective use of multiaxis machining centres to 119 and 129 parts for two and three nomenclatures, respectively. Increasing the batch of parts with an increasing number of nomenclatures is insignificant.

Thus, the general tendency is determined to increase the batch size that can be machined according to the proposed manufacturing process while increasing the number of fixture nomenclatures.
The productivity of machine tools significantly depends on the share of the cutting time in the structure of machining time. It is established that the cutting time influences the choice of the manufacturing process and the determination of the effective scope's limit.

Further research revealed a general trend that a shorter time of machining indicates the effectiveness of the proposed manufacturing process. E.g., the research dependencies of the machining cost on the batch size when machining one to three nomenclatures of parts at $\mathrm{Tc}=1 \mathrm{~min}$ allowed to establish that the proposed manufacturing process was useful when machining a batch of parts up to 90 pcs. Increasing the number of standard sizes of parts allows expanding the scope of the effective use of multiaxis machining centres to 119 and 129 parts for two and three nomenclatures, respectively. Increasing the batch of parts with an increasing number of nomenclatures is insignificant.

According to the production conditions at the cutting time $\mathrm{T}_{\mathrm{c}}=10 \mathrm{~min}$, the proposed manufacturing process is useful when the batch size comprises 70 pieces. When machining a batch of parts of several sizes, the efficiency limit is shifted to increase the batch size. The efficiency of the proposed manufacturing process with two nomenclatures of parts equals up to 95 pcs., and up to 103 pcs. in the case with three nomenclatures of parts.

The use of a typical manufacturing process is cost-effective for long-term machining of parts, e.g., 
at $\mathrm{T}_{c}=50 \mathrm{~min}$. For these conditions, the limit is the batch size with more than 37 pcs. for one nomenclature, 50 pcs. - two nomenclatures, 54 pcs. - three nomenclatures.

The reduction of the share of auxiliary time in machining time is considered a tendency in metalworking. For the workpieces under consideration, this share equals $70-450 \%$ for a typical manufacturing process and $30-130 \%$ for the proposed manufacturing process. The influence of auxiliary time on the cost of machining is investigated, and the useful scope of the manufacturing process is established under the condition of the same value of auxiliary time for both investigated variants. With the share of auxiliary time comprising $25 \%$ of the cutting time norm, the efficiency of the proposed manufacturing process is observed when the batch size reaches up to 51 pcs. When comparing the production conditions, the effectiveness of the proposed manufacturing process is observed at the rate of auxiliary time up to $8 \mathrm{~min}$.

The analysis of machining conditions of parts at the norm of auxiliary time of $50 \%$ and $150 \%$ of the norm of the cutting time confirmed that the limit of efficiency of using the proposed manufacturing process decreases at the increase of the auxiliary time norm. It is proved that when machining several sizes of parts, the scope of effective use is shifted in the direction of increasing the batch size, in particular, by $34 \%$ for two nomenclatures of parts and $45 \%$ for three nomenclatures.

The analysis of the effectiveness of the proposed manufacturing process, depending on the preparatory time, allowed determining the limits of the effective use of different manufacturing processes. The same norm of preparatory time for the considered manufacturing process is accepted in calculations. The results confirmed the general trend that the effectiveness of the proposed manufacturing process is proven for machining small batches of 48 pcs., 34 pcs., and 22 pcs. at the norms of preparatory time, and they comprise $75 \%, 150 \%$, and $300 \%$ of the cutting time norm, respectively.

Studies show that the proposed approach to using flexible fixtures for machining of several nomenclatures of parts allows increasing the batch size of parts by $32 \%$ when machining parts of two nomenclatures or by $44 \%$ when machining parts of three nomenclatures.

\section{DISCUSSION OF THE RESULTS}

Ganesan and Mohankumar (2013) found a significant impact made by the minimum operating time, production cost, and tool wear. Dehtiarov (2017) evaluated the cost of machining based on a comparative analysis of the effectiveness of different fixture systems (dedicated fixture, modular fixture, and modular adjustable fixture). His research mainly focused on the cost of design, assembly, and batch size. However, time costs were not considered. Also, Erdem (2020) proved that the cost of a fixture depended on the hardware cost of a flexible fixture, the cost of setup and external equipment needed for a flexible fixture, the software development cost and the software development time, and the total cost allocated to a flexible fixture. Therefore, the cost of machining should be calculated considering time costs, particularly cutting time, auxiliary time, and preparatory time. It is proved that multiproduct manufacturing needs quick changeovers to meet industry challenges and market needs.

The proposed methodological approach was verified on machining fork-type parts with similar design and technological features combined in a group. This group consists of five different fork-type parts (Fig. 4). The total number of parts in this group is 150 pcs.

A comparative analysis of typical and proposed manufacturing processes was performed for two cases, namely, machining one part and machining a batch of parts (Table 1). Based on the calculations, machining costs are different when using different fixtures under the same production conditions. A batch size significantly influences the choice of the manufacturing process. It was assumed that a typical manufacturing process required five dedicated fixtures, which allowed performing all drilling, milling, and boring operations. The implementation of the

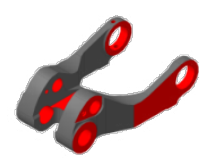

a)

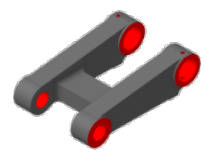

b)

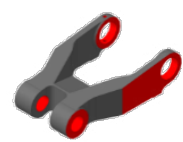

c)

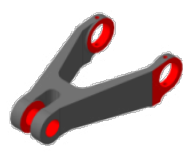

d)

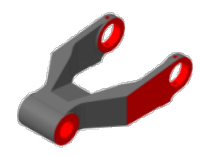

e)

Fig. 4. Typical fork-type designs 
Tab. 1. Comparison of the effectiveness of the proposed and typical manufacturing processes

\begin{tabular}{|c|c|c|c|c|c|}
\hline $\begin{array}{l}\text { FORK-TYPE DESIGN } \\
\text { (ACCORDING TO } \\
\text { FIG. 4) }\end{array}$ & $\begin{array}{c}\text { NAME AND CODE OF } \\
\text { THE PART }\end{array}$ & $\begin{array}{l}\text { BATCH SIZE, } \\
\text { PCS. }\end{array}$ & $\begin{array}{l}\text { MANUFACTURING } \\
\text { PROCESS }\end{array}$ & COST, UAH & $\begin{array}{l}\text { COMPARATIVE } \\
\text { ECONOMIC } \\
\text { EFFICIENCY }\end{array}$ \\
\hline \multirow{2}{*}{ a } & \multirow{2}{*}{ Plug 99408076} & \multirow{2}{*}{30} & Typical & 1011.28 & \multirow{2}{*}{1.27} \\
\hline & & & Proposed & 797.38 & \\
\hline \multirow{2}{*}{$b$} & \multirow{2}{*}{ Plug 3721-4511 } & \multirow{2}{*}{40} & Typical & 782.12 & \multirow{2}{*}{1.05} \\
\hline & & & Proposed & 745.0 & \\
\hline \multirow{2}{*}{ c } & \multirow{2}{*}{ Plug 99408076-2 } & \multirow{2}{*}{70} & Typical & 487.48 & \multirow{2}{*}{0.83} \\
\hline & & & Proposed & 587.86 & \\
\hline \multirow{2}{*}{$d$} & \multirow{2}{*}{ Plug 73.02.34-01 } & \multirow{2}{*}{100} & Typical & 369.62 & \multirow{2}{*}{0.68} \\
\hline & & & Proposed & 540.72 & \\
\hline \multirow{2}{*}{$\mathrm{e}$} & \multirow{2}{*}{$\begin{array}{c}\text { Plug 120.3- } \\
88.01 .05\end{array}$} & \multirow{2}{*}{10} & Typical & 2844.62 & \multirow{2}{*}{1.86} \\
\hline & & & Proposed & 1530.72 & \\
\hline \multirow{2}{*}{$a, b, c, d, e$} & \multirow{2}{*}{ Batch of parts } & \multirow{2}{*}{250} & Typical & 5495.11 & \multirow{2}{*}{2.5} \\
\hline & & & Proposed & 2197.58 & \\
\hline
\end{tabular}

proposed manufacturing process needs one flexible fixture, which allows performing multiaxis machining. The effectiveness of the proposed manufacturing process was substantiated by comparing the typical and the proposed manufacturing processes when machining fork-type parts (Fig. 4 a, b, e) with a batch size of 30 pcs., 40 pcs., and 10 pcs., accordingly. In these cases, the cost of machining is lower than for the typical manufacturing process. Therefore, comparative economic efficiency is higher than 1 . When machining fork-type parts (Fig. $4 \mathrm{c}$, d) with batch sizes of 70 and 100 pcs., the cost of a typical manufacturing process is lower, as the costs are calculated for the entire batch of parts.

In the traditional approach, the cost of machining for a batch of parts is calculated as the sum of the costs of a typical manufacturing process for each considered part. As known, a flexible fixture ensures the setup of similar parts; therefore, all five configurations of the described fork-type parts can be set up in one fixture. In this case, the cost of machining is calculated for the batch size of 250 pcs. Based on the calculations, the advantage of the proposed manufacturing process is undeniable. A particularly significant contribution is made by introducing flexible fixtures and allowing multiaxis machining of parts of several nomenclatures. The comparative economic efficiency equals 2.5. Thus, according to the calculated data, the proposed manufacturing process efficiency is inapplicable for all designs of parts and their batch sizes. It was established that the highest efficiency of the offered manufacturing process was reached with batches of up to 20 pieces.

\section{CONCLUSIONS}

The efficiency of implementing flexible fixtures depends on various factors. The paper presented a mathematical model for evaluating the efficiency of manufacturing processes involved in the machining complex parts using flexible fixtures at the cost of machining. The cost of time, the cost of implementing the manufacturing process, and the batch size were considered.

Based on the paper, flexible fixtures are effective for machining small batches of parts with short-term machining and frequent readjustments to new workpieces. A tendency has been established that a higher number of nomenclature of parts contributes to expanding the scope of the effective use of flexible fixtures. Further research will be focused on implementing the proposed approach to other types of parts in multiproduct manufacturing.

\section{ACKNOWLEDGEMENT}

This research is partially funded by Center for Industrial Engineering (Sumy State University) and International Association for Technological Development and Innovations.

\section{LITERATURE}

Ansaloni, M., Bonazzi, E., Leali, F., Pellicciari, M., \& Berselli, G. (2013). Design of fixture systems in automo- 
tive manufacturing and assembly. Advanced Materials Research, 712-715, 2913-2916. doi: 10.4028/www. scientific.net/AMR.712-715.2913

Bakker, O. J., Papastathis, T. N., Ratchev, S. M., \& Popov, A. A. (2013). Recent research on flexible fixtures for manufacturing processes. Recent Patents on Mechanical Engineering, 6(2). doi: 10.2174/2212797611306020003

Basova, Y., Nutsubidze, K., Ivanova, M., Slipchenko, S., \& Kotliar, A. (2018). Design and numerical simulation of the new design of the gripper for manipulating of the rotational parts. Diagnostyka, 19(4), 11-18. doi: $10.29354 / \mathrm{diag} / 94030$

Brettel, M., Klein, M., \& Friederichsen, N. (2016). The relevance of manufacturing flexibility in the context of Industrie 4.0. Procedia CIRP, 41, 105-110. doi: 10.1016/j.procir.2015.12.047

Bi, Z. M., \& Zhang, W. J. (2001). Flexible fixture design and automation: Review, issues and future directions. International Journal of Production Research, 39(13), 2867-2894. doi: 10.1080/00207540110054579

Dehtiarov, I. M. (2017). Technological support of lever-type part machining in batch manufacturing using flexible fixtures. Ph.D. thesis, Manugacturing Engineering. Kharkiv, Ukraine: National Technical University "Kharkiv Polytechnic Institute".

Denysenko, Y., Dynnyk, O., Yashyna, T., Malovana, N., \& Zaloga, V. (2019). Implementation of CALS-technologies in quality management of product life cycle processes. In V. Ivanov et al. (Eds.), Advances in Design, Simulation and Manufacturing. DSMIE-2018. Lecture Notes in Mechanical Engineering (pp. 3-12). Cham, UK: Springer. doi: 10.1007/978-3-319-935874_1

Dynnyk, O., Denysenko, Y., Zaloga, V., Ivchenko, O., \& Yashyna, T. (2020). Information support for the quality management system assessment of engineering enterprises. In V. Ivanov et al. (Eds.), Advances in Design, Simulation and Manufacturing II. DSMIE-2019. Lecture Notes in Mechanical Engineering (pp. 65-74). Cham, UK: Springer. doi: 10.1007/978-3-030-22365-6_7

Elkins, D. A., Huang, N., \& Alden, J. M. (2004). Agile manufacturing systems in the automotive industry. International Journal of Production Economics, 91, 201-214.

Erdem, I. (2020). Efficiency of flexible fixtures: design and control. Ph.D. thesis, Industrial and Materials Science. Gothenburg, Sweden: Chalmers University of Technology.

Erdem, I., Levandowski, C., Berlin, C., Kihlman, H., \& Stahre, J. (2017). A novel comparative design procedure for reconfigurable assembly fixtures. CIRP Journal of Manufacturing Science and Technology, 19, 93-105. doi: 10.1016/j.cirpj.2017.06.004

Förstmann, R., Wagner, J., Kreisköther, K., Kampker, A., \& Busch, D. (2017). Design for automation: the rapid fixture approach. Procedia Manufacturing, 11, 633640. doi: 10.1016/j.promfg.2017.07.161

Ganesan, H., \& Mohankumar, G. (2013). Optimization of machining techniques in CNC turning centre using genetic algorithm. Arabian Journal for Science and Engineering, 38, 1529-1538. doi: 10.1007/s13369013-0539-8
Hasan, F., Jain, P. K., \& Kumar, D. (2014). Service level as performance index for reconfigurable manufacturing system involving multiple part families. In B. Katalinic (Ed.), 24th DAAAM International Symposium on Intelligent Manufacturing and Automation, 2013 Procedia Engineering, pp. 814-821. doi: 10.1016/j.proeng.2014.03.058

Hashemi, H., Shaharoun, A. M., \& Sudin, I. (2014). A casebased reasoning approach for design of machining fixture. International Journal of Advanced Manufacturing Technology, 74(1-4), 113-124. doi: 10.1007/ s00170-014-5930-4

Ivanov, V., Dehtiarov, I., Pavlenko, I., Kosov, I., \& Kosov, M. (2019). Technology for complex parts machining in multiproduct manufacturing. Management and Production Engineering Review, 10(2), 25-36. doi: 10.24425/mper.2019.129566

Ji, Y., Chen, X., Qi, G., \& Song, L. (2013). Modular design involving effectiveness of multiple phases for product life cycle. International Journal of Advanced Manufacturing Technology, 66, 1475-1488. doi: 10.1007/ s00170-012-4432-5

Kostyuk, G. (2019). Prediction of the microhardness characteristics, the removable material volume for the durability period, cutting tools durability and processing productivity depending on the grain size of the coating or cutting tool base material. In B. Gapiński, M. Szostak, V. Ivanov (Eds.), Advances in Manufacturing II. MANUFACTURING 2019. Lecture Notes in Mechanical Engineering (pp. 300-316). Cham, UK: Springer. doi: 10.1007/978-3-030-16943-5_27

Kostyuk, G., Nechyporuk, M., \& Kostyk, K. (2019). Determination of technological parameters for obtaining nanostructures under pulse laser radiation on steel of drone engine parts. 10th International Conference on Dependable Systems, Services and Technologies, DESSERT 2019: Institute of Electrical and Electronics Engineers Inc., 208-212. doi: 10.1109/DESSERT.2019.8770053

Kotliar, A., Basova, Y., Ivanova, M., Gasanov, M., \& Sazhniev, I. (2019a). Technological assurance of machining accuracy of crankshaft. In M. Diering, M. Wieczorowski, \& C. Brown (Eds.), Advances in Manufacturing II. MANUFACTURING 2019. Lecture Notes in Mechanical Engineering (pp. 37-51). Cham, UK: Springer. doi: 10.1007/978-3-030-18682-1_4

Kotliar, A., Gasanov, M., Basova, Y., Panamariova, O., \& Gubskyi, S. (2019b). Ensuring the reliability and performance criterias of crankshafts. Diagnostyka, 20(1), 23-32. doi: 10.29354/diag/99605

Krol, O., \& Sokolov, V. (2018). Development of models and research into tooling for machining centers. EasternEuropean Journal of Enterprise Technologies, 3(1-93), 12-22. doi: 10.15587/1729-4061.2018.131778

Li, H., Chen, W., \& Shi, S. (2016). Design and application of flexible fixture. Procedia CIRP, 56, 528-532. doi: 10.1016/j.procir.2016.10.104

Li, M. (2007). Efficiency measurement for multi-dimensional group technology. International Journal of Advanced Manufacturing Technology, 35, 621-632. doi: 10.1007/s00170-006-0734-9

Matteo, A., Enrico, B., Francesco, L., Marcello, P., \& Berselli, G. (2013). Design of fixture systems in automotive 
manufacturing and assembly. In X. Liu, K. Zhang, \& M. Li (Eds.) Advances in Manufacturing Science and Engineering, Pts 1-4 Advanced Materials Research, pp. 2913-2916. doi: 10.4028/www.scientific. net/AMR.712-715.2913

Mehrabi, M. G., Ulsoy, A. G., Koren, Y., \& Heytler, P. (2002). Trends and perspectives in flexible and reconfigurable manufacturing systems. Journal of Intelligent Manufacturing, 13(2), 135-146. doi: 10.1023/A:1014536330551

Neely, A. (1999). The performance measurement revolution: Why now and what next? International Journal of Operations and Production Management, 19, 205228.

Nixon, F. (1971). Managing to achieve quality and reliability. New York, London: McGraw-Hill.

McIntosh, R. I., Culley, S. J., Mileham, A. R., \& Owen, G. W. (2000). A critical evaluation of Shingo's 'SMED' (Single Minute Exchange of Die) methodology. International Journal of Production Research, 38, 2377-2395.

Qin, G. H., Zhang, W. H., Wan, V., \& Sun, S. P. (2010). A novel approach to fixture design based on locating correctness. International Journal of Manufacturing Research, 5(4), 429-448. doi: 10.1504/ IJMR.2010.035812

Rong, Y., \& Zhu, Y. (1999). Computer-aided fixture design. Manufacturing engineering and materials processing New York, USA: Marcel Dekker.

Sarker, B.R., \& Khan, M. A (2001). Comparison of existing grouping efficiency measures and a new weighted grouping efficiency measure. IIE Transactions, 33, 11-27. doi: 10.1023/A:1007633622787

Setchi, R. M., \& Lagos, N. (2004). Reconfigurability and reconfigurable manufacturing systems - State-of-the-art review. 2004 2nd Ieee International Conference on Industrial Informatics: Collaborative Automation - One Key for Intelligent Industrial Environments.

Shaik, A. M., Rao, V., \& Rao, C. S. (2015). Development of modular manufacturing systems-a review. International Journal of Advanced Manufacturing Technology, 76(5-8), pp. 789-802. doi: 10.1007/s00170-0146289-2.

Sokolov, V., Krol, O., \& Baturin, Y. (2019). Dynamics research and automatic control of technological equipment with electrohydraulic drive. 2019 International Russian Automation Conference, RusAutoCon 2019: Institute of Electrical and Electronics Engineers Inc.

Son, Y. K., \&Park, C. P. (1987). Economic measure of productivity, quality and flexibility in advanced manufacturing systems. Journal of Manufacturing Systems, 6(3), 193-207. doi: 10.1016/0278-6125(87)90018-5.

Sonmez, V., Testik, M. C. \& Testik, O. M. (2018). Overall equipment effectiveness when production speeds and stoppage durations are uncertain. International Journal of Advanced Manufacturing Technology, 95, 121-130. doi: 10.1007/s00170-017-1170-8

Stepanov, M., Ivanova, L., Litovchenko, P., Ivanova, M., \& Basova, Y. (2019). Model of thermal state of the system of application of coolant in grinding machine. In: Ivanov V. et al. (eds), Advances in Design, Simulation and Manufacturing. DSMIE 2018. Lecture Notes in Mechanical Engineering. Springer, Cham. pp. 156165. doi: 10.1007/978-3-319-93587-4_17

Yarovyi, Y., \& Yarova, I. (2020). Energy criterion for metal machining methods. In: Ivanov V. et al. (eds), Advances in Design, Simulation and Manufacturing II. DSMIE 2019. Lecture Notes in Mechanical Engineering. Springer, Cham. pp. 378-387. doi: 10.1007/9783-030-22365-6_38 